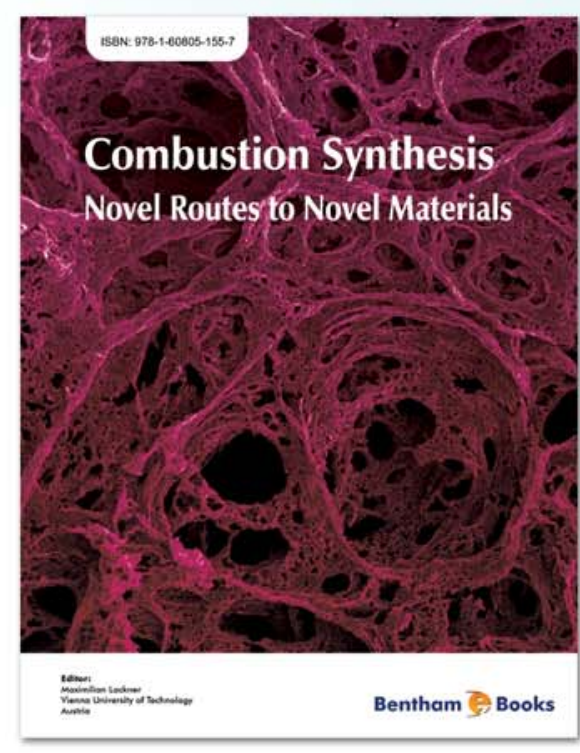

Editor:

Maximilian Lackner

Austria

\section{USS}

89.00

only

\title{
Combustion Synthesis Novel Routes to Novel Materials
}

\section{wW.henthamscience.com/ohooks/9781608051551}

\section{About the ebook}

Combustion synthesis covers a wide range of technologies to produce advanced materials, ranging from oxides, nitrides and intermetallics to various nanostructured compounds, such as nanopowders and carbon nano tubes (CNT). This Ebook provides an updated overview about combustion synthesis with contributions from leading experts in industry and academia.

\section{Contents}

- Combustion Synthesis Involving Thermite Reactions

Emulsion Combustion Synthesis

Combustion Synthesis of Nitrogen Ceramics and Nanosized Ceramic Powders

- Gel-Combustion Synthesis

- Cellulose-Assisted Combustion Synthesis of Functional Materials for Energy Storage or Conversion

- Related Processes to Combustion Synthesis

- Combustion Synthesis Melt Casting

For Sales and Advertising Inquiries: Contact: marketing@benthamscience.org 